\title{
Stereotype Threat at Work
}

\author{
Wen Zhang* \\ Xi'an International Studies University, School of Chinese Studies, Xi’an 710061, China.
}

\begin{abstract}
Stereotype threat that is an important aspect of diversity management still exists in broader workplace. Many experimental results show that if members of a stereotyped group are brought into an achievement situation where the stereotype can be applied, they often dramatically underperform when they believe their ability in that particular domain is measured. Therefore, eliminating negative stereotypes at work where all employees can perform their true potential, received so much research of different experts. The writers try to suggest some recommendations on how to reduce stereotype threat in working environment so that diversity of human capital really becomes effective competitive weapon.
\end{abstract}

Keywords: FPGA; Human Resources Management; Stereotype Threat; Effective Competitive

\section{Introduction}

In competitive environment, there is a growing awareness of the importance of the human resources management (HRM). As the changing in demand of the economy takes place very quickly and more often. It raises the requirement for each company to introduce new products or services frequently to retain the customers in traditional market and seek for the potential customers in untapped market to survive and growth strategy. It is clear that diversity in human capital is a huge source of innovations and

Copyright (C) 2020 Wen Zhang

doi: 10.18282/1-e.v9i4.1734

This is an open-access article distributed under the terms of the Creative Commons Attribution Non-Commercial License (http://creativecommons.org/licenses/by-nc/4.0/), which permits unrestricted non-commercial use, distribution, and reproduction in any medium, provided the original work is properly cited.

color tone-changing training, color generalization training, color symbolization training, etc. Students are required to change color without deformation to express their true feelings. The ultimate goal is to enable students to express their own emotions and psychology through the use of subjective color language, and to deeply understand the relationship between color expression and spiritual symbol. The fourth stage of color design course teaching is the stage of professional color design and creation. Students can practice the training of color symbolic meaning through color proposition creation. For example, students can feel the image characteristics of the colors of four seasons and taste colors through the creation of color symbolic assignments of "spring, summer, autumn and winter" and "sour, sweet, bitter, hot". The difference between color comprehension and expression is the key and important link of design ${ }^{[4]}$.Western modern art masters such as Picasso, Matisse, Mondrian and other people's color processing techniques are very free, through the feeling of conception and overall arrangement of meaningful color forms. Such as mondrian's paintings inspired the modern design with the originality, mainly in terms of color hue is used to contrast and area of contrast methods, in the "red, yellow, blue composition" series of color processing, the painting on the subjective color tend to be more prominent, the artist according to the need of the picture convey to adjust color piece size and shape, build the whole picture, to establish the color harmonious order.

3. ConclusionDepending on the source of art under the background of Chinese and western color is limitless reserve, in is becoming more and more communication between Chinese and western culture under the background of modern, rich product set the color view of Chinese and western history of modern education plays a profound enlightenment and reference, color of colleges and universities education should take root in Chinese culture, the traditional color of inheriting and carrying forward national culture view, selective absorbing the essence of western performance color view, penetration and applied to the practice of teaching, to create suitable for modern aesthetic form of design and color, achieve the goal of finally for the service.

\section{References}

[1] Xiang Wenjun. Discussion on Color Teaching Strategies in Art Education of Secondary Vocational Schools [J]. Modern Vocational Education, 2016 (17).

[2] LIU Chunyan. Discussion on color teaching strategies in art education of secondary vocational schools [J]. Good Parents, 2017; (73).

[3] Guo Wei. Exploring the Analysis of Color Contrast Teaching Strategies in Art Teaching of Secondary Vocational Schools [J]. Art Education Research, 2017; (22).

[4] Wu Ling. Optimization strategy analysis of color teaching in contemporary secondary vocational art education [J]. Business, 2015; (52). 
creations that need to meet the market's demand. It is also assumed to be the sustained competitive advantage that companies need to put more investment to indentify, nurture and protect.

Stereotype threat that is an important aspect of diversity management still exists in broader workplace. Many experimental results show that if members of a stereotyped group are brought into an achievement situation where the stereotype can be applied, they often dramatically underperform when they believe their ability in that particular domain is measured. Therefore, eliminating negative stereotypes at work where all employees can perform their true potential, received so much research of different experts.

This report is broken down into several sections to guide the reader throughout the discussion. First, the basic analysis from the article "Stereotype threat at work", written by Roberson and Kulik (2007) ${ }^{[1]}$, are introduced, focusing in objectives, concepts, methodology, findings and conclusion. After that, the researchers will attempt to find out more research related to the topic as well as present their opinions about the paper. Based on their own research, the writers also try to suggest some recommendations on how to reduce stereotype threat in working environment so that diversity of human capital really becomes effective competitive weapon.

\section{Discussion}

\subsection{Objective}

Recognition that diversity in human capital is a sustained competitive advantage, in this paper, the authors aims to create positive environment for diverse employees and improve the management of diversity on organizations by focusing on the effects of stereotype threat at work. In fact, stereotype threat at work, known as the fear of being judged and treated according to a negative stereotype about members of one group, is an important aspect of diversity management that need to put more attention by diversity or management scholars.

\subsection{Concept}

"Stereotype threat" is the basic concept that is defined by both the authors and other experts: As mention by the two authors, "stereotype threat" describes the psychological experience of a person who, while engaged in a task, is aware of a stereotype about his or her identity group suggesting that he or she will not perform well on that task. While it was defined by Spencer, Steele, \& Quinn (1999) ${ }^{[2]}$, as situation specific, felt in situations where one could be judged by, treated and seen in terms of, or self-fulfill a negative stereotype about one's group.

\subsection{Methodologies}

Basically, this paper was completed by much research of two writers via experimental results. These experiments were carried by different experts, in which they compared the performance of two groups (one group was negatively stereotyped, the other was not) in two-task condition (one condition presented the task as stereotype relevant, the other did not). Besides that, the two authors also did research on other data that came from interviews such as an interview with singer and actress Beyoncé Knowles or quoted opinion of other researches about stereotype threat at work to support for their research.

\subsection{Findings}

Societal stereotypes, according to the research (Roberson and Kulik, 2007), can have a negative effect on employee feelings and behaviour, making it difficult for an employee to perform to his or her true potential; as well as stereotype threat can result in employees working harder, but not better. When stereotype threat is present, performance declines ${ }^{[3]}$.

Stereotype threat is most likely to influence performance on very difficult tasks - those are at the limits of a person's abilities. There is a negative dynamic operates between task difficulty and stereotype threat, when a task is difficult, stereotype threat evokes concern over performance. But this concern also has a greater impact on the performance of difficult tasks. Difficult jobs require concentration and focus; all of one's cognitive resources must be directed toward accomplishing the work. In work settings then, difficult, complex, and challenging tasks are where stereotype threat is most likely to occur.

\section{Conclusions}

Stereotype threat now is more and more serious problem in workplace and society. It restricts ability performance of person who is hired on this task. For that reason, solutions that are reducing stereotype threat are concerned by management or boss. Methods which show below in report is solutions help to reduce performance deficits.

Stereotype threat appears when members in groups do poorly; they will not perform well on their task. Therefore, encouraging self-affirmation is the good way to motivate employees' creation. It makes them can do their task with their all ability. Encouraging people to think about their characteristics, skills, values, or roles can do this that they value or view as important. (Schimel, Arndt, Banko, \& Cook, 2004) $)^{[4]}$

Another method that has been shown to reduce stereotype threat is to reframe or use different language to describe the task or test being used. Stereotype threat arises in situations where task descriptions highlight social identities stereotypically associated with poor performance. Modifying task descriptions so that such stereotypes are not invoked or are disarmed can eliminate stereotype threat. Stereotype threat based on gender, for example, can be reduced either by ensuring females that a test is gender-fair (Quinn \& Spencer, 2001) ${ }^{[5]}$ or by explicitly nullifying the assumed diagnostically of the test (Steele \& Aronson, 1995a) ${ }^{[6]}$. Besides, emphasizing high standards with assurances about capability for those standards is necessary to excite people finish their task well done.

To sum up, maximum restriction of stereotype threat and maximum motivation of human capability is very necessary developing organization or different areas in society. Doing so involves emphasizing the importance of effort and motivation in performance. Individual who is encouraged to think in incremental terms will tend to react more effectively to challenge and are 


\title{
To What Extent Can Non-Native Speaker Teachers Teach Speaking Successfully in Foreign Language Learning Context?
}

\author{
Xinyi Yang" \\ Xi'an Eurasia University, Xi'an, Shaanxi 710065
}

\begin{abstract}
In this essay, non-native speaker teachers teaching speaking under the foreign language learning context would be analyzed. Instead of simply regarding native speaker teachers as the absolute priority in teaching speaking, non-native speaker teachers could also effectively impart speaking skills to students with their bilingual proficiency, second language learning experience and direct access to the cultural context of their students. After further studies, the unique competence of non-native speaker teachers would be revealed through this essay.
\end{abstract}

Keywords: Non-Native Speaker Teachers

\section{Non-native language teachers' oral skills in a foreign language learning environment}

First of all, with bilingual language proficiency, non-native speaker teachers would be more experienced to engage students to pursue speaking skills in the foreign language learning contexts. According to Medgyes (as cited in Kirkpatrick, 2007) ${ }^{[1]}$, since nonnative speaker teachers have gone through the same second language learning process as their students who are still dealing with, those teachers would anticipate most language learning difficulties their students would encounter during their foreign language studies. As is known to most foreign language learners, it is quite difficultly to ignore the gap between their mother tongue and their target foreign language. In order to narrow the gap, those foreign language learners have to transform not only their way of thinking but also their mother tongue language patterns to get used to a newly unfamiliarized thinking pattern and those target language symbols. Compared with those native speakers who are simply focused on their target language patterns, those non-native speaker teachers with their mastered mother tongue knowledge and their unique second language learning skills could help those students who are struggling with their second language studies. Under this circumstance, non-native speaker teachers would lead students to learn foreign language speaking in an effective way by intended converting students' way of thinking from mother tongue to target language and providing students with detailed as well as easy access to those difficult questions students might encounter during their studies. Besides, when students meet some complicated issues, teachers could explain to students in mother tongue. Step by step, students can be converted from their familiarized mother tongue to their unfamiliarized target language patterns.

\section{Non-native language teachers' understanding of the students' cultural background}

Copyright (C) 2020 Xinyi Yang

doi: 10.18282/1-e.v9i4.1735

This is an open-access article distributed under the terms of the Creative Commons Attribution Non-Commercial License (http://creativecommons.org/licenses/by-nc/4.0/), which permits unrestricted non-commercial use, distribution, and reproduction in any medium, provided the original work is properly cited.

less likely to fear confirming negative stereotypes of their group.

\section{References}

[1]Brief, A. P., \& Barsky, A. (2000). Establishing a climate for diversity: The inhibition of prejudiced reactions in the workplace. Research in Personnel and Human Resources Management, 19, 91-129; quoted in Roberson, L. \& Kulik, C. (2007), Stereotype threat at work, Academy of Management Perspectives, 21(2), 24-40.

[2]Spencer, S. J., Steele, C. M., \& Quinn, D. M. (1999). Stereotype threat and women's math performance. Journal of Experimental Social Psychology, 35, 4-28; quoted in Roberson, L. \& Kulik, C. (2007), Stereotype [11]threat at work, Academy of Management Perspectives, 21(2), 24-40.

[3]Roberson, L. \& Kulik, C. (2007), Stereotype threat at work, Academy of Management Perspectives, 21(2), 24-40.

[4]Schimel, J., Arndt, J., Banko, K. M., \& Cook, A. (2004). Not all self-affirmations were created equal: The cognitive and social benefits of affirming the intrinsic (vs. extrinsic) self. Social Cognition, 22, 75-99.

[5]Quinn, D. M., \& Spencer, S. J. (2001). The Interference of stereotype threat with women's generation of mathematical problemsolving strategies. Journal of Social Issues, 57, 55-71.

[6]Steele, C. M., \& Aronson, J. (1995a). Stereotype threat and the intellectual test performance of African-Americans. Journal of Personality and Social Psychology, 69, 797-811. 